Original Research Paper

\title{
Forecasting Bangladesh's Inflation through Econometric Models
}

\author{
${ }^{1,2}$ Nazmul Islam \\ ${ }^{I}$ Department of Humanities, Bangladesh University of Engineering and Technology (BUET), Bangladesh \\ ${ }^{2}$ Department of Economics, Florida International University, Miami, Florida, \\ 11200 S.W. 8th Street, DM 316 Miami, Florida 33199, United States
}

Corresponding Author:

Tel: (786)-856-0539

Email: nazmul786humbuet@gmail.com

\begin{abstract}
This research tries to sketch the concrete steps that help carry out to use ARIMA time series models for forecasting Bangladesh's inflation. The focus, in this paper, is short-term basis annual inflation forecasting. For this purpose, different ARIMA models are used and the candid model is proposed. Based on the diagnostic and evaluation criteria, the most accurate model is selected. The order of the best ARIMA model was found to be ARIMA $(1,0,0)$ to forecast the future inflation for a period up to five years. The predicted inflation rate is 4.40 in 2016 and in the consecutive years, it will rise slightly. The findings of the paper will give us a shortterm view of inflation in Bangladesh and support in implementing policies to maintain stable inflation.
\end{abstract}

Keywords: Inflation, Macroeconomic Policy, ARIMA Model, Partial Autocorrelations

\section{Introduction}

One of the main objectives of macroeconomic policy is to maintain a persistent economic growth along with low inflation. Therefore, inflation rate undertakes serious importance in Macroeconomic policy. The effects of monetary policy have time lags. This requires policy makers to update the path of inflation repeatedly. Applying univariate time series ARIMA models, policy makers can have earlier signal about inflation prediction. Time series analysis helps in predicting future values and to evaluate the effect of events or policy variations. The monetary authorities in Bangladesh are confronting two challenges- maintaining stable inflation and ensuring high growth in the economy. The difficulty of controlling inflation and the time lag of monetary policy suggest the need to maintain stable inflation. This paper is one such endeavor to get for perfect univariate time series inflation prediction in Bangladesh applying annual data from 1971 to 2015 . Moreover, in the literature, no study has been carried out yet considering yearly data from 1971 to 2015 .

The rest of this study is arranged as follows: section 2 demonstrates the literature review, section 3 discusses the data and research methodology I developed, section 4 presents the findings of inflation forecasts, in the last section I draw the conclusion.

\section{Literature Review}

Throughout the last few decades, many studies were executed on the comparative correctness of various models of inflation prediction. Meyler et al. (1998) worked on to forecast Irish inflation applying ARIMA time series models. Makridakis et al. (1982; Meese and Geweke, 1984) have considered alternative approaches: the objective penalty function methods and the Box Jenkins approaches which suggest that ARIMA prediction did exceptionally well. Jenkins and Watts (1968; Yule, 1926; 1927; Bartlett, 1964; Quenouille, 1949; Ljung and Box, 1978; Pindyck and Tubinfeld, 1981) have also underscored the usage of ARIMA models. Salam et al. (2007) used ARIMA time series models to predict Pakistan's inflation. Faisal (2011) applied ARIMA model forecasting Bangladesh's inflation using monthly CPI from March 2001 to August 2011. Akhter (2013) in her paper, used the SARIMA models to predict the short-term inflation rate of Bangladesh using the monthly CPI from January 2000 to December 2012. I have made an effort to outline the 
steps that need to be carried out to use ARIMA time series models for forecasting Bangladesh's inflation.

\section{Data and Research Methodology}

\section{Data Collection}

In this paper, inflation is calculated by the annual growth rate of the GDP implicit deflator that shows the rate of price change in the economy. The GDP implicit deflator is the ratio of GDP in current local currency to GDP in constant local currency. This study is an effort to have perfect univariate time series to forecast Bangladesh's inflation. I use the annual time series World Bank data (TWBIBRD.IDA, 2017) from 1971 to 2015 to forecast Bangladesh's inflation. However, six observations from 1973 to 1978 were dropped because of outlier problem.

\section{Model Identification}

Figure 1 represents the line plot of inflation rate in Bangladesh. We must make this time series stationary to build the ARIMA model. First, we need to do the Augmented Dickey-Fuller (ADF) test to check the stationarity of the time series data (unit root problem).

The noon-stationarity of the time series data is the null hypothesis $\left(\mathrm{H}_{0}\right)$ in the test. The ADF test result:
$\mathrm{DF}=-4.6062, \mathrm{Lag}$ order $=0, \mathrm{p}$-value $=0.01$

I, thus, cannot accept the $\mathrm{H}_{0}$ and therefore can claim that the time series data. Therefore, is stationary in its mean and variance. Thus, there is no necessity for differencing the time series.

Figure 2 shows the plot of correlogram ACF for lags 1 to 15 of the time series of the inflation in Bangladesh.

The above correlogram interprets that the autocorrelation tails off to zero and auto-correlation does not exceed the significance limits except at lag1.

The partial correlogram PACF in Fig. 3 demonstrates that partial autocorrelation coefficient exceeds significant limits only at lag1 and the partial autocorrelations tail off to zero.

From the above analysis, I can define the following possible ARIMA models: ARIMA $(0,0,0)$, ARMA $(1,0,1)$, ARIMA $(0,0,1)$ and ARIMA $(1,0,0)$. I will select the model with the lowest Akaike Information Criterion (AIC) values to select as the best suitable model for forecasting out of four above. Table 1 recapitulates the output of each of the fitted ARIMA models:

Table 1 shows that the lowest AIC value is for the ARIMA $(1,0,0)$ model with $\mathrm{p}=1, \mathrm{~d}=0$ and $\mathrm{q}=1$. Hereafter, for making forecasts for future values of the time series data, this can be the best predictive model.

Table 1: AIC values of fitted ARIMA models

\begin{tabular}{llllll}
\hline & \multicolumn{2}{c}{ Coefficients } & & Log \\
ARIMA & AR1 & MA1 & Likelihood & AIC \\
Models & Intercepts & & & -110.52 & 225.05 \\
\hline $0,0,0$ & 7.0928 & 0.4133 & -0.0687 & -107.92 & 223.83 \\
$1,0,1$ & 7.0157 & & 0.2804 & -108.48 & 222.96 \\
$0,0,1$ & 7.0671 & 0.3527 & & -107.94 & 221.87 \\
$1,0,0$ & 7.0244 & 0.04 & & \\
\hline
\end{tabular}

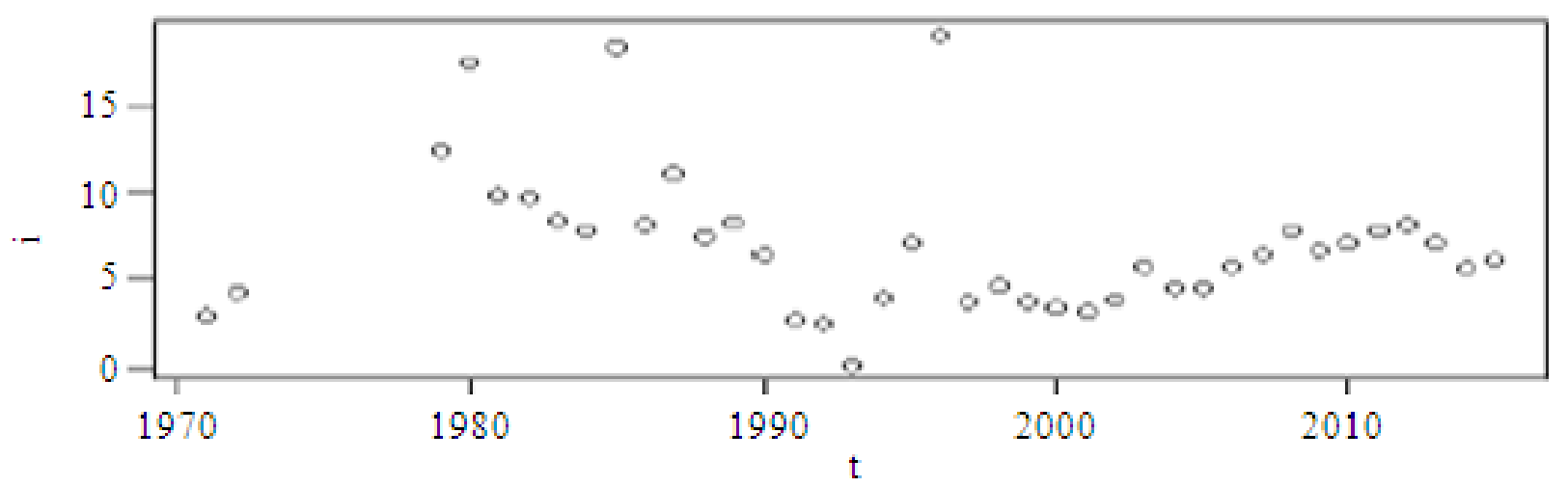

Fig. 1: Line plot of Inflation rate in Bangladesh from 1971 to 2015 


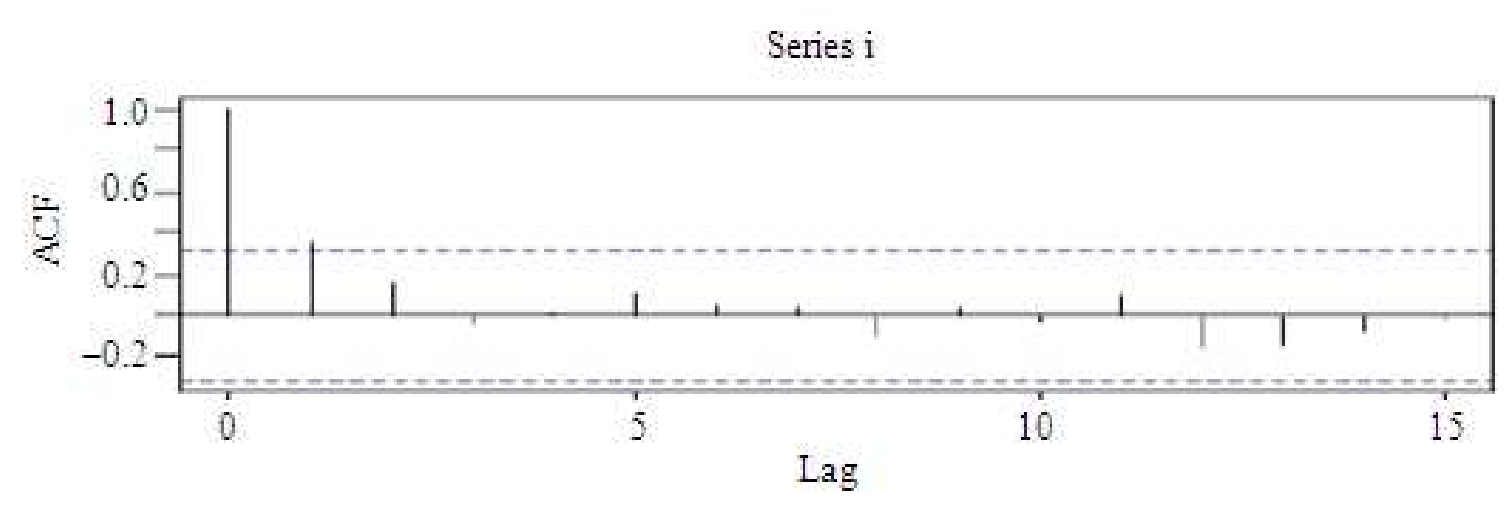

Fig. 2: Autocorrelations (ACF) of the series

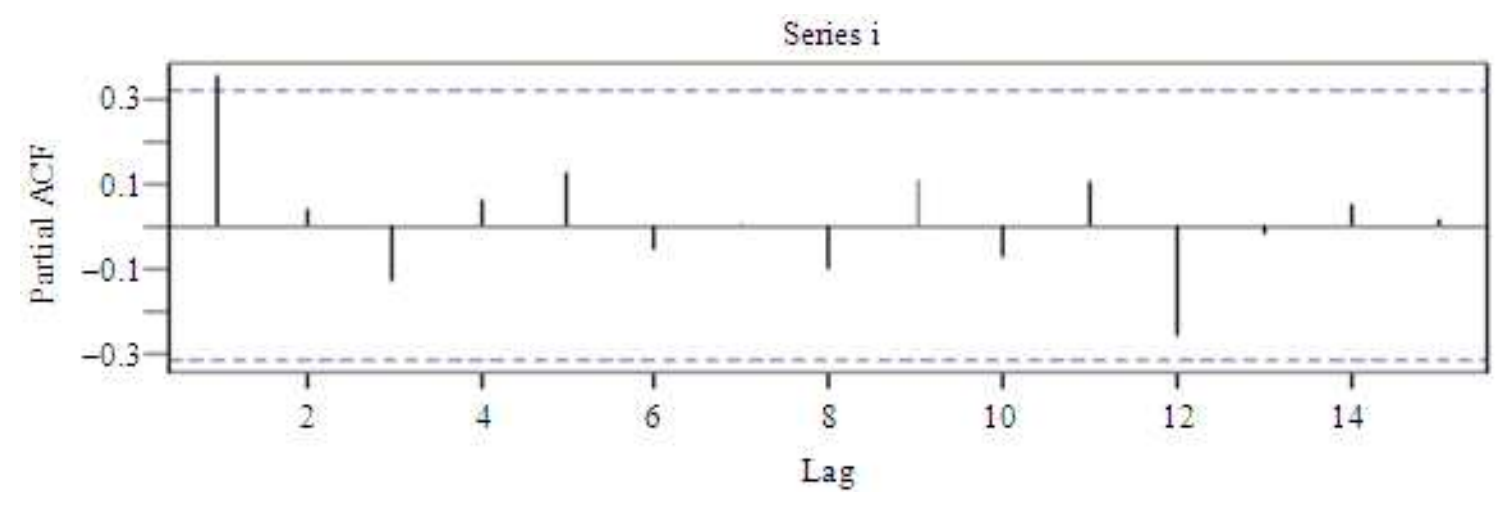

Fig. 3: Partial Autocorrelations (PACF) of the series

\section{Results}

The selected model ARIMA $(1,0,0)$, means that the fitting ARMA $(1,0)$ model of first-order difference to the time series. Therefore, this model can be expressed as:

$$
\Delta \Pi_{t}=\beta_{0}+\beta_{1} \Delta \Pi_{t-1}+\varepsilon_{t}
$$

where, the stationary time series for the inflation rate we are studying $=\Pi_{t}$; parameters to be estimated $=$ $\beta s$; and white noise with mean zero and constant variance $=\varepsilon_{\mathrm{t}}$.

Table 2 represents the prediction for the next 5 years.

Table 2 shows that the ARIMA $(1,0,0)$ model predicts a gradual increase of inflation rate in Bangladesh though the rate of increase is not very high. To know whether or not the fitted ARIMA $(1,0,0)$ model represents the evidence for non-zero autocorrelations in the forecast errors at lags 1 to 15 , I find the Box-Ljung test statistics.

The statistics and large p-values in the test in Table 3 suggest that we should accept the null hypothesis that is all of the autocorrelation functions in lag 1 to 15 are zero.
Table 2: 5-Year forecasting for inflation

\begin{tabular}{ll}
\hline Prediction & Forecast \\
\hline 2016 & 4.396525 \\
2017 & 4.649182 \\
2018 & 4.678153 \\
2019 & 4.681567 \\
2020 & 4.681971 \\
\hline
\end{tabular}

Table 3: Box-Ljung test statistics

\begin{tabular}{cccc}
\hline Test & X Squared & Degrees of freedom & p-value \\
\hline 23.008 & 24 & 0.5193 \\
\hline
\end{tabular}

That is to say, we can conclude that there is no (or almost nil) evidence for non-zero autocorrelations in the forecast errors at lags 1 to 15 in our fitted model.

Figure 4 shows that any of the autocorrelation coefficients between lag 1 and 15 are not violating the significant limits, indicating all the ACF values are well within the significant limits. Likeliness ACFs, Fig. 5 represents that all the PACFs of residuals of fitted ARIMA models for lag 1 to lag 15 are within the significant limits. It implies that ACF and PACF illustrate that there are no non-zero autocorrelations in the forecast residuals (or standard errors) at lag 1 to 15 in the fitted ARIMA $(1,0,0)$ model. 


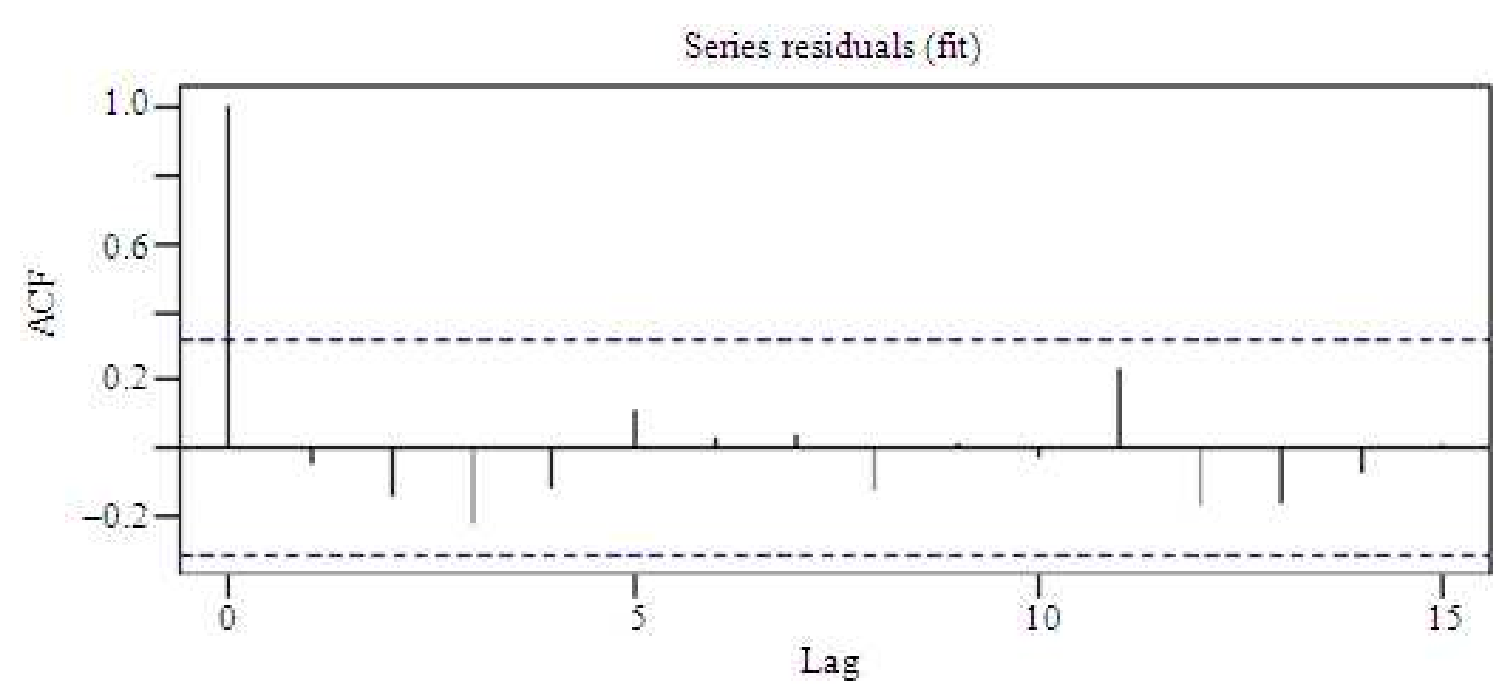

Fig. 4: Estimated ACF of residuals - ARIMA $(1,0,0)$

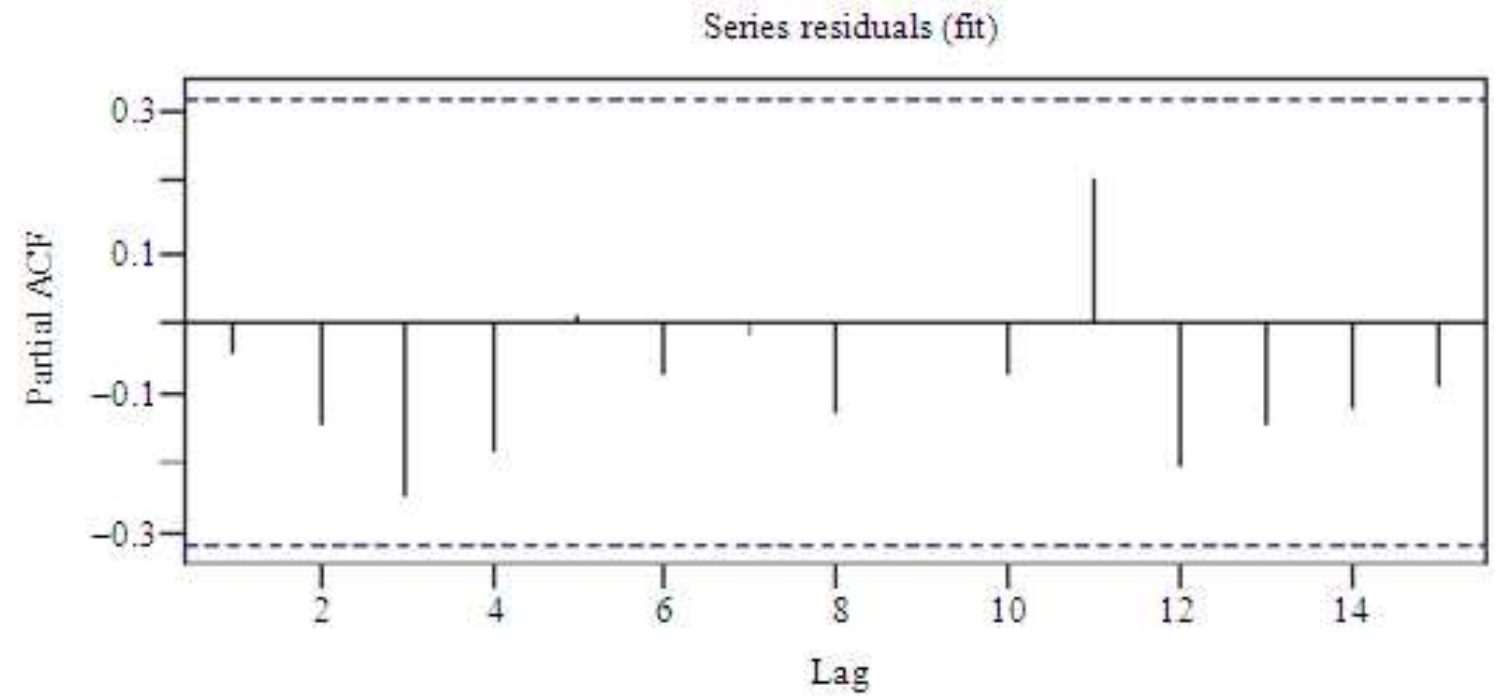

Fig. 5: Estimated PACF of Residuals (Forecast Errors) - ARIMA $(1,0,0)$

\section{Conclusion}

Through using the Box-Jenkins approach of time series forecasting, the best forecasting model has been chosen. In this study, the ARIMA $(1,0,0)$ is the best model for making forecasts for up to 5 years for the inflation in Bangladesh using a 38-year data. ARIMA was applied because of its competencies to make predictions using a time series data with any kind of pattern and with autocorrelations between the consecutive values in the time series. Moreover, the paper statistically tested and confirmed that no successive residuals (forecast errors) in the fitted ARIMA time series were correlated. Hereafter, we can conclude that the ARIMA $(1,0,0)$ appears to present a satisfactory predictive model for the inflation in
Bangladesh. The ARIMA model predicts that the inflation rate is 4.40 in 2016, then rises to 4.65 in 2017.It would increase in the subsequent years, though the rate of increase is not very high (Table 2). Although ARIMA model has limitations on the accuracy of forecasting, it is still used more widely for prediction the future successive values in the time series.

\section{Acknowledgement}

The researcher gratefully acknowledges the professors of Econometrics and Macroeconomics in his undergraduate and graduate classes.

\section{Funding Information}

The author did not receive any financial support. 


\section{Author's Contributions}

In the literature, no study has been carried out yet considering yearly data from 1971 to 2015 to forecast Bangladesh's inflation.This research considers the anuual data of this time period to predict the short term basis annual inflation of Bangladesh. The study may help the policy makers to maintain a stable macroeconomic setting in Bangladesh economy.

\section{Ethics}

The author is not aware of any ethical issue that may arise after the publication of this manuscript. The article is original and contains unpublished materials. Moreover, the author has read and approved the manuscript.

\section{References}

Akhter, T., 2013. Short-term forecasting of inflation in Bangladesh with seasonal ARIMA processes. MPRA Paper, Munich University Library, Germany.

Bartlett, M.S.,1964. On the theoretical specification of sampling properties of autocorrelated time series. J. Royal Stat. Socity, 8: 27-41.

Faisal, F., 2011. Forecasting Bangladesh's inflation using time series ARIMA models. A Project of Infrastructure Investment Facilitation Center (IIFC)-An Enterprise of Economic Relations Division (ERD), the Ministry of Finance, the Government of Bangladesh.

Jenkins, G.M. and D.G. Watts, 1968. Spectral Analysis and its Application. 1st Edn., Holden-Day, San Francisco, California, USA, ISBN-10: 0816244642, pp: 525.
Ljung, G.M. and G.E.P. Box, 1978. On a measure of lack of fit in time series models. Biometrika, 65: 297-303.

Makridakis, S, A. Anderson, R. Carbone, R. Fildes and M. Hibon et al., 1982. The accuracy of extrapolation (time series) methods: Results of a forecasting competition. J. Forecasting Competition J. Forecasting, 1: 111-153.

Meese, R. and J. Geweke, 1984. A comparison of auto regressive univariate forecasting procedures for macroeconomic time series. J. Bus. Eco. Stat., 2: 191-200.

Meyler, A., G. Kenny and T. Quinn, 1998. Forecasting irish inflation using ARIMA models. Central Bank Financial Services Authority Ireland, Technical Paper Series No. 3/RT/98, Ireland, pp: 1-48.

Pindyck, R.S. and D.L. Rubinfeld, 1981. Econometric Models and Economic Forecasts. 2nd Edn., McGrawHill, New York.

Quenouille, M.H., 1949. Approximate tests of correlation in time-series. J. Royal Stat. Socity, 11: 68-84.

Salam, A.S., S. Salam and M. Feridun, 2007. Modeling and forecasting Pakistan's inflation by using time series ARIMA models.

TWBIBRD.IDA, 2017. The World Bank IBRD.IDA.

Yule, G.U., 1926. Why do we sometimes get nonsensecorrelations between time-series? A study in sampling and the nature of time-series. J. Royal Stat. Socity, 89: 1-69.

Yule, G.U., 1927. On a method of investigation periodicities in disturbed series, with special reference to Wolferes sunspot number. Phill. Trans. A, 226: 267-298. 